\title{
Mathematical model for force state on the fit surface of a composite back-up roll in four-high mill strip cold rolling
}

\author{
Yonggang Dong ${ }^{\mathrm{a}}$, Guoling Luo and Jianfeng Song \\ College of Mechanical Engineering, Yanshan University, Qinhuangdao, Hebei, China
}

\begin{abstract}
For building the mathematical model of force and stress on the interference fit surface of composite back-up roll by the shrinkage fit method, the roll sleeve and roll mandrel was studied respectively. The loads acted on the contact zone was discretized and the roll sleeve and roll mandrel were discretized segment by segment, then the flexural stress and deflection models of the roll sleeve and roll mandrel was proposed based on the deformation compatibility condition. According to the force equilibrium function, torque equilibrium function between the roll sleeve and the roll mandrel, the mathematical models of forces and stress acted on the roll sleeve and interference fit surface were derived to solve the shear force, axial stress, bending moment acted on the roll sleeve and the bending moment, circumferential friction force, vertical stress acted on the interference fit surface. Therefore, it is an important theoretical foundation to improve the manufacturing technology and practical application of the composite back-up roll. Keywords: roll sleeve, roll mandrel, interference fit surface, discrete elements, compatibility of deformation, strip cold rolling.
\end{abstract}

\section{Introduction}

At present the domestic back-up roll for the plate or strip cold rolling mill is manufactured by the traditional method generally, such as unit cast method, solid forging method or compound forging method [1-2]. Since the whole back-up roll have to be changed for the roll radius is less than a minimum working radius after being ground some times, the material consumption of back-up roll is tremendous and the cost of products is increased obviously. A novel composite back-up roll, which is assembled by the roll sleeve and roll mandrel by the shrinkage fit method, have been studied to decrease the consumption of back-up roll and the roll changing periodic. In the process of plate or strip cold rolling, the roll sleeve of this composite back-up roll can be changed individually if it reaches the minimum allowable working radius, and the roll mangle can be used a longer time and it is not necessary to be changed frequently [3-4].

It is optimistic and worth to be desired for the composite back-up roll by the shrinkage fit to be applied in the practice. However, the processing parameter of shrinkage fit for the composite back-up roll, such as the physical dimension and the shrink range, is obtained by the empirical formula or practice experience. Moreover, the influence of the structure size, material performance parameter and the crown of roll sleeve and roll mangle on the elastic deformation of roll system in the rolling has not been studied.

\footnotetext{
a Corresponding author: d_peter@163.com
} 
In plate or strip cold rolling process by four-roll mill with a solid integral back-up roll, the elastic deformation mathematical model of rolls system had been studied profoundly by some researchers [5-7]. But this model can't be applied to solve the force energy parameters of rolls system with a composite back-up roll directly for the difference of structure and manufacturing technology. So it is very necessary to build proper mathematical models to obtain the the exact force state when the composite back-up roll is applied to the strip cold rolling.

\section{The loads on the composite back-up roll}

As can be seen in Fig.1, the size of roll radius and roll body length about one half of lower roll system in strip rolling process was shown. According to the characteristic of composite back-up roll, the composite back-up roll can be separated two parts to study its deflection respectively.

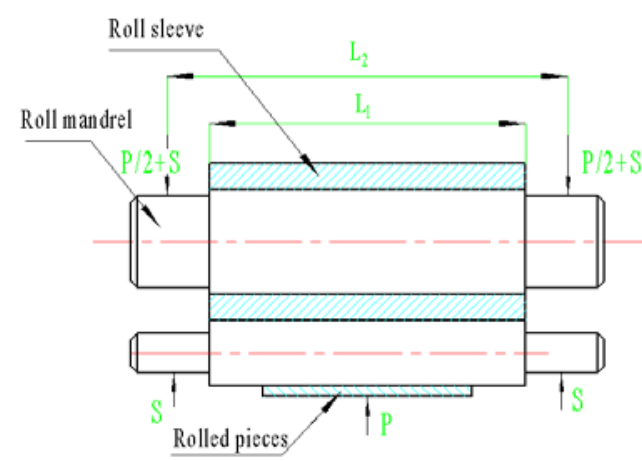

Figure 1. The size and force of rolls system.
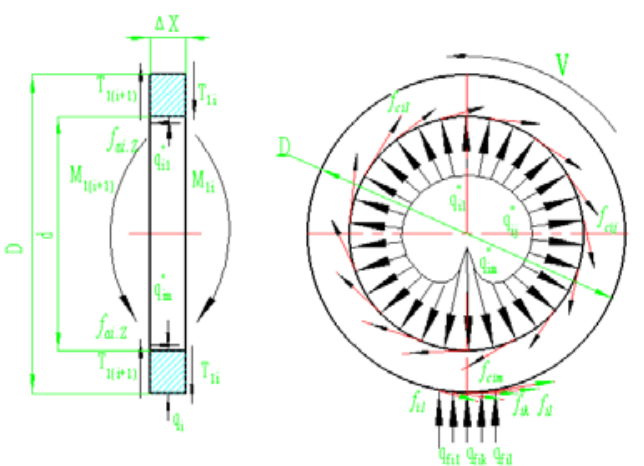

Figure 3. Loads on the discretized element of roll sleeve.

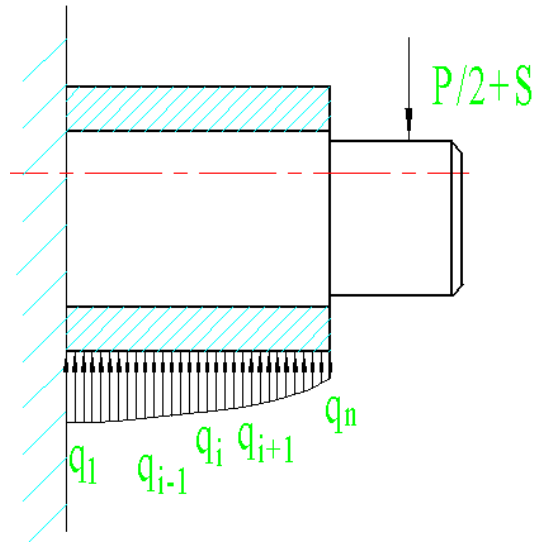

Figure 2. The load simplification of working roll.
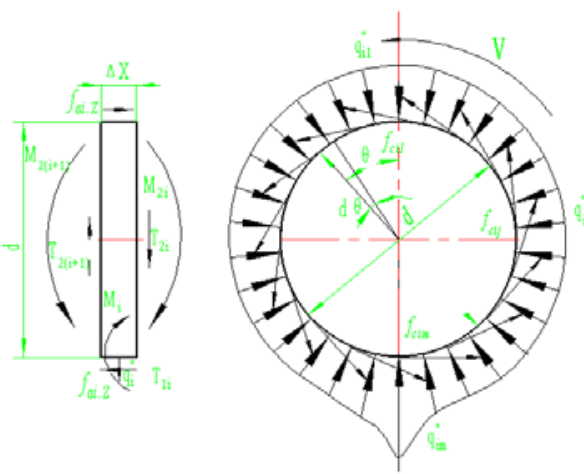

Figure 4. Loads on the discretized element of roll mandrel.

As shown in Fig. 3 and Fig.4, $T_{1}(i), T_{1}(i+1)$ are the shear stress on the right side and left side of discretized element of roll sleeve respectively. $T_{2}(i), T_{2}(i+1)$ are the shear stress on the right side and left side of discretized element of roll mandrel respectively. $M_{1}(i), M_{1}(i+1)$ are the torques on the on the right side and left side of discretized element of roll sleeve respectively. $q_{i}$ is the contact force between the working roll and back-up roll of $i$ th element of roll sleeve. $q_{i j}^{\prime \prime}$ is the radial contact force on the interference fit surface between the roll sleeve and roll mandrel. $f_{a i j}, f_{c i j}$ are the axial friction force and 
circumferential friction force on the interference fit surface respectively. $f_{i 1}$ is the friction force on the contact zone between the working roll element and back-up roll element.

For discretized elements of roll sleeve, the boundary conditions can be shown as

$$
T_{1}(1)=T_{2}(1)=0, M_{1}(1)=0
$$

For discretized elements of roll mandrel, the boundary conditions can be shown as

$$
\begin{gathered}
T_{2}(1)=P / 2+S \\
M_{2}(1)=(P / 2+S) \cdot\left(L_{2}-L_{1}\right) / 2
\end{gathered}
$$

\section{Compatibility equation for the flexural stress}

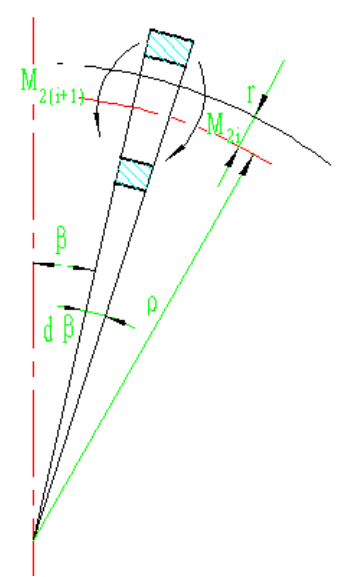

Figure 5. Deflection of elements of roll sleeve.
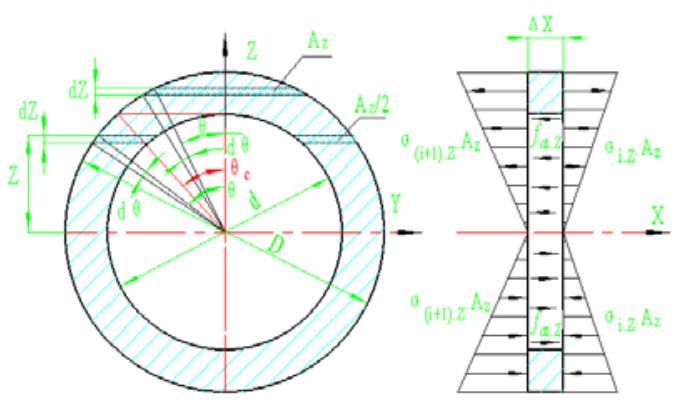

Figure 6. Axial force on the elements of roll sleeve.

As shown in Fig.5 and Fig.6, torque on a random element of curved roll sleeve was shown in Fig.5 and the axial normal stress acted on this element was shown in Fig.6. According to the assumption of single force and the elastic module of pressing equals that of, the axial normal stress on the elements of roll sleeve and roll mandrel can be obtained individually by the law of hook [8].

$$
\begin{gathered}
\sigma_{1}(r, \theta)=\varepsilon E_{1}=\frac{r \cos \theta E_{1}}{\rho_{1}}(0 \leq r \leq D) \\
\sigma_{2}(r, \theta)=\varepsilon E_{2}=\frac{r \cos \theta E_{2}}{\rho_{2}}(0 \leq r \leq d)
\end{gathered}
$$

Where $\rho_{1}, \rho_{2}$ are radius of curvature on the neutral layer of roll sleeve and roll mandrel respectively. The torque on the elements of roll sleeve and roll mandrel can be expressed as

$$
M_{1}(i+1)=\int_{A z} \sigma_{1} r \cos \theta \mathrm{dAz}=\frac{E_{1}}{\rho_{1}} \int_{A z} r^{2} \cos ^{2} \theta \mathrm{dAz}=\frac{E_{1} I_{1}}{\rho_{1}}
$$




$$
M_{2}(i+1)=\int_{A_{z}} \sigma_{2} r^{2} \mathrm{dAz}=\frac{E_{2} I_{2}}{\rho_{2}}
$$

It is assumed that there is no relative slip between the interference fit surface of roll sleeve and roll mandrel, then $\rho_{1}=\rho_{2}$.

The ratio of torque on a random elements between the cross-section of roll sleeve and roll mandrel can be shown as

$$
\frac{M_{2}(i+1)}{M_{1}(i+1)+M_{2}(i+1)}=\frac{E_{2} I_{2}}{E_{1} I_{1}+E_{2} I_{2}}
$$

So the iterative equation of $i$ th element was shown as

$$
\begin{gathered}
M(i+1)=M(i)-\left(T_{1}(i)+T_{2}(i)\right) \mathrm{dx}+\frac{1}{2} q_{i} \mathrm{dx} \\
T_{1}(i)+T_{2}(i)=\sum_{i=1}^{n} q_{i}-\sum_{j=1}^{m} q_{i j}^{\prime \prime} \\
M_{\text {total }}(i+1)=M_{1}(i+1)+M_{2}(i+1)
\end{gathered}
$$

The boundary condition were shown as

$$
\begin{gathered}
\sum_{i=0}^{\mathrm{n}} \sum_{l=1}^{k} q_{i l}=\sum_{i=0}^{n} q_{i}=P+2 S\left(q_{i}=\sum_{l=1}^{k} q_{i l}\right) \\
T_{1}(0)+T_{2}(0)=P / 2+S \\
M(0)=(P / 2+S)\left(L_{2}-L_{1}\right) \\
M_{1}(0)=0
\end{gathered}
$$

Where $P, S$ are rolling force and bending force respectively. $L_{2}, L_{1}$ are distance of two bearing base of back-up roll and the axial length of back-up roll.

According to the Eq.9, Eq.10, and Eq.11, and boundary condition, $M_{1}(i+1), M_{2}(i+1)$ of any element $i$ can be solved.

\section{Compatibility equation of flexural deformation}

Deflection deformation subject to the single load can be obtained by the summing up method, and total deflection deformation can be solved by calculating every deflection deformation and getting the 
summation. Since the deflection of roll sleeve is equal to that of roll mandrel, the compatibility equation can be shown as

$$
f_{1}=f_{2}
$$

The deflection deformation of every load on the element of roll sleeve can be expressed as

$$
\begin{gathered}
f_{1}=f_{1}\left(q_{i}-\sum_{j=0}^{m-1} q_{i j}^{\prime \prime} \cdot \cos \left(\frac{j}{m} 2 \pi\right)\right)+f_{1}\left(T_{1}\right)-f_{1}\left(M_{1}\right)-f_{1}(M) \\
f_{1}\left(q_{i}-\sum_{j=0}^{m-1} q_{i j}^{\prime \prime} \cdot \cos \left(\frac{j}{m} 2 \pi\right)\right)=-\frac{\left(q_{i}-\sum_{j=0}^{m-1} q_{i j}^{\prime \prime} \cdot \cos \left(\frac{j}{m} 2 \pi\right)\right)(\mathrm{dx})^{4}}{8 E_{1} I_{1}} \\
f_{1}\left(T_{1}\right)=-\frac{T_{1}(i)(\mathrm{dx})^{4}}{3 E_{1} I_{1}} \\
f_{1}\left(M_{1}\right)=-\frac{M_{1}(i)(\mathrm{dx})^{2}}{2 E_{1} I_{1}} \\
f_{1}(M)=-\frac{3 M(i)(\mathrm{dx})^{2}}{8 E_{1} I_{1}}
\end{gathered}
$$

Then total deflection deformation of element of roll mandrel can be obtained by

$$
\begin{gathered}
f_{2}=-f_{2}\left(\sum_{j=0}^{m-1} q_{i j}^{\prime \prime} \cdot \cos \left(\frac{j}{m} 2 \pi\right)\right)+f_{2}\left(T_{2}\right)-f_{2}\left(M_{2}\right)+f_{2}(M) \\
f_{2}\left(q_{i j}^{\prime \prime}\right)=-\frac{\left(\sum_{j=0}^{m-1} q_{i j}^{\prime \prime}\right)(\mathrm{dx})^{4}}{8 E_{2} I_{2}} \\
f_{2}\left(T_{2}\right)=-\frac{T_{2}(i)(\mathrm{dx})^{4}}{3 E_{2} I_{2}} \\
f_{2}\left(M_{2}\right)=-\frac{M_{2}(i)(\mathrm{dx})^{2}}{2 E_{2} I_{2}}
\end{gathered}
$$




$$
f_{2}(M)=-\frac{3 M(i)(\mathrm{dx})^{2}}{8 E_{2} I_{2}}
$$

The compatibility of deflection deformation of roll sleeve and roll mandrel can be shown as

$$
f_{1}=f_{2}
$$

Where $I_{1}$ and $I_{2}$ are inertia torque of roll sleeve and roll mandrel, ant it can be obtained by $I_{1}=\frac{\pi}{64}\left(D^{4}-d^{4}\right), I_{2}=\frac{\pi}{64} d^{4}$.

\section{Equilibrium equations of force and bending moment}

The equilibrium equation of force on the roll sleeve and roll mandrel along the vertical direction can be expressed respectively as

$$
\begin{array}{r}
T_{2}(i+1)+\sum_{j=0}^{m-1} q_{i j}^{\prime \prime} \cos \left(\frac{j}{m} 2 \pi\right)-T_{2}(i)=0 \\
T_{1}(i+1)-q_{i}+\sum_{j=0}^{m-1} q_{i j}^{\prime \prime} \cos \left(\frac{j}{m-1} 2 \pi\right)-T_{1}(i)=0
\end{array}
$$

The equilibrium equation of bending moment on the roll mandrel can be shown as

$$
\begin{gathered}
M_{2}(i+1)+M(i)-M_{2}(i)+T_{2}(i) \cdot \Delta x-\sum_{j=0}^{m-1} q_{i j}^{\prime \prime} \cdot \cos \left(\frac{j-1}{m} 2 \pi\right) \cdot \frac{\Delta x}{2}=0\left(\Delta x=\frac{L_{1}}{2 n}\right) \\
M(i)=\sum_{j=0}^{m-1} f_{a i j} \cdot \frac{d}{2}=\sum_{j=0}^{m-1} \mu_{a} \cdot q_{i j}^{\prime \prime} \cdot \frac{d}{2}
\end{gathered}
$$

The equilibrium equation of torque on the element of roll sleeve and roll mandrel can be shown as

$$
\begin{gathered}
\sum_{j=0}^{m-1} f_{c i j} \cdot \frac{d}{2}=\sum_{j=0}^{m-1} \mu_{c} \cdot q_{i j}^{\prime \prime} \cdot \frac{d}{2} \\
\sum_{i=0}^{n-1} \sum_{j=0}^{m-1}\left(\mu_{c} \cdot q_{i j}^{\prime \prime}\right) \cdot \frac{d}{2}+M_{f}=\sum_{i=0}^{n-1} \sum_{l=0}^{k-1} f_{i l} \cdot \frac{D}{2}=\sum_{i=0}^{n-1}\left(\mu_{f} \cdot q_{i}\right) \cdot \frac{D}{2} \\
M_{f}=\frac{\mu_{0} C_{l}(P+2 S) d_{m}}{2}+1.34 \times 10^{-5}(\gamma \cdot V)^{\frac{2}{3}} d_{m}^{3}
\end{gathered}
$$

Where $\mu_{c}, \mu_{0}, \mu_{f}$ are friction coefficients between the inner roll sleeve and outer roll mandrel, bearing inner ring and bearing outer ring, working roll and back-up roll respectively. $\mathrm{C}_{l}$ is the load coefficient, $d_{m}$ is the mean diameter of inner diameter and outer diameter is the kinematic viscosity of lubricant oil in the bearing of back-up roll, $V$ is the rotation angular velocity of back-up roll.

According to above equilibrium equations, $T_{1}(i+1), T_{2}(i+1), q_{i}, M(i)$ of any element $i$ can be solved. 


\section{Results and discussions}

These mathematical models were applied to analysis the force state of interference fit surface in four-high strip cold rolling mill from some rolling plant. The thickness of incoming work-piece and outgoing work-piece are $3.0 \mathrm{~mm}$ and $2.0 \mathrm{~mm}$ respectively, and width of incoming work-piece is $900 \mathrm{~mm}$, total rolling force is 800 ton. The diameter of working roll and back-up roll are $520 \mathrm{~mm}$ and $1200 \mathrm{~mm}$ respectively, and the length of work roll and back-up roll are $1200 \mathrm{~mm}$, distance between two housing screw is $2456 \mathrm{~mm}$.

Material of roll sleeve is $70 \mathrm{Cr} 3 \mathrm{NiMo}$, and its elastic modulus is $2.1 \times 1011 \mathrm{~Pa}$, its Poisson ratio is 0.26. Material of roll mandrel is 45 , and its elastic modulus is $1.9 \times 1011 \mathrm{~Pa}$, its Poisson ratio is 0.3 .

As shown in Fig.7, the maximum value of shear force exists at the outside rim and it decreases from maximum value to 0 at the most lateral edge. As shown in Fig.8, the direction of bending moment changes and the bending moment between two adjacent elements increases with the rise of bending force.

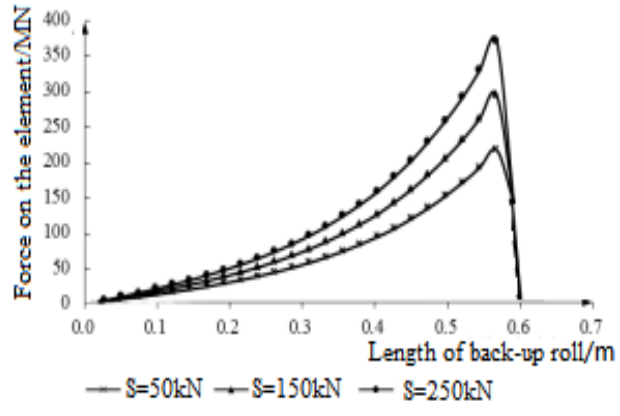

Figure 7. Shear force acted on the roll sleeve.

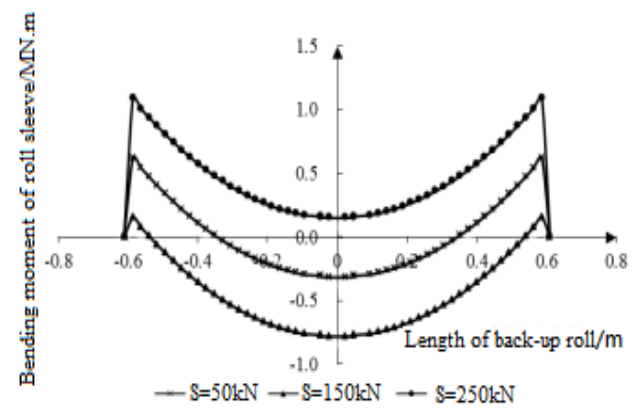

Figure 8. Bending moment acted on the roll sleeve.

As shown in Fig.9, vertical force on the interference fit surface between roll sleeve and roll mandrel increases with the rise of distance from the symmetry plane. As shown in Fig.10, the peak value of negative direction of bending moment between roll sleeve and roll mandrel increases with the rise of bending forces, and the peak value of positive direction of bending moment decreases with the rise of bending forces.

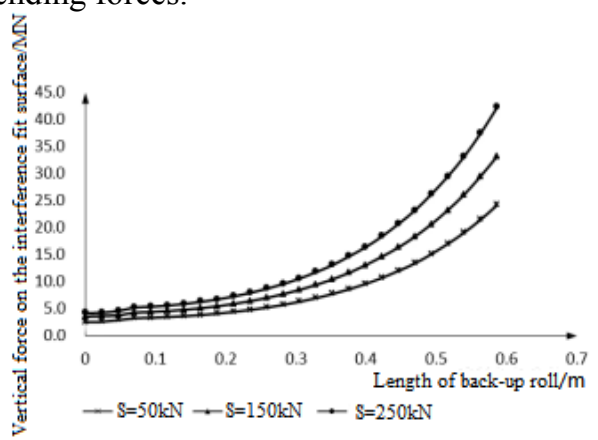

Figure 9. Vertical force on the interference fit surface.

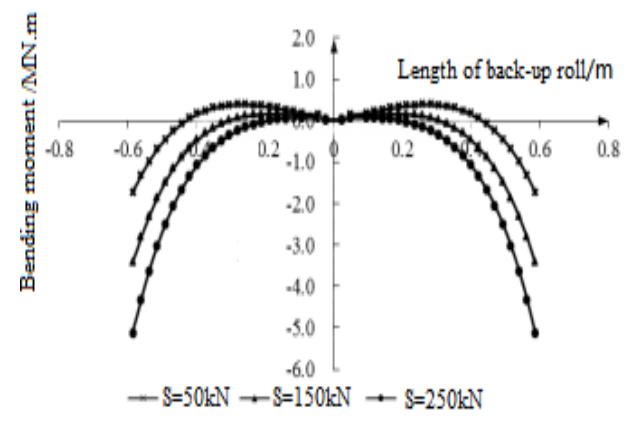

Figure 10. Bending moment between roll sleeve and roll mandrel.

As shown in Fig.11, peak value of positive direction of axial normal stress on the inner races of roll sleeve increases with the rise of bending forces, and peak value of negative direction of axial normal stress decreases with the rise of bending forces. As shown in Fig. 12, circumferential friction on the interference fit surface reaches the maximum value on the symmetry plane of longitudinal direction of roll, and it decreases with the rise of distance from the symmetry plane. Moreover, the circumferential friction of middle element is greater than that of the edge element. 


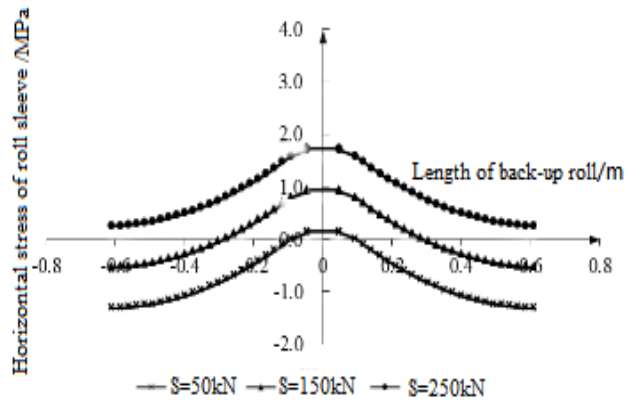

Figure 11. Axial stress on the inner races of roll sleeve.

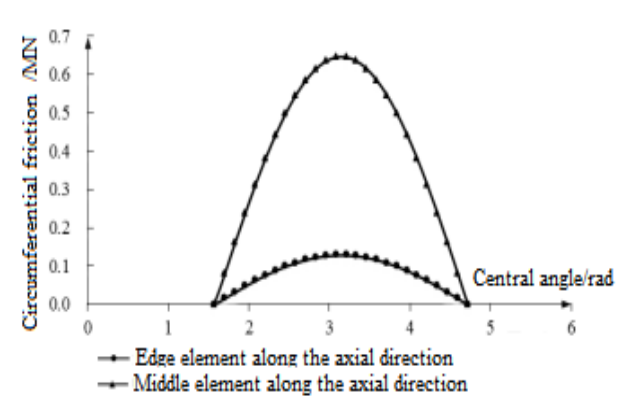

Figure 12. Circumferential friction of interference fit surface.

\section{Conclusions}

The maximum value of shear force acted on the interference fit surface exists at the outside race and it decreases from maximum value to 0 at the most lateral edge, and the direction of bending moment acted on the roll sleeve changes and the bending moment between two adjacent elements increases with the rise of bending force;

The peak value of negative direction of bending moment between roll sleeve and roll mandrel increases with the rise of bending forces, and the peak value of positive direction of bending moment decreases with the rise of bending forces;

The circumferential friction on the interference fit surface reaches the maximum value on the symmetry plane of longitudinal direction of roll, and it decreases with the rise of distance from the symmetry plane. Moreover, the circumferential friction of middle element is greater than that of the edge element.

\section{Acknowledgements}

Foundation Item: Item Sponsored by Natural Science Foundation of China (50775196); Natural Science Foundation of Hebei Province (E2015203431); First-class Foundation of Post Doctoral Research of Hebei Province.

\section{References}

1. H.Y. Kima, C. Kimb, W.B. Bae, Development of optimization technique of warm shrink fitting process for automotive transmission parts(3D FE analysis), J. Journal of Materials Processing Technology. 187 (2007) 458-462.

2. Shimizu M, Shitamura O, Matsuo S, Development of high performance new composite roll, J. ISIJ International. 32 (1992) 1244-1249.

3. Fu Hanguang, Xing Jiandong, Zhao Aimin, Centrifugal casting of high speed steel/ nodular cast iron compound roll collar, J. Journal of Iron and Steel Research. 9 (2002) 32-35.

4. X Chen, R. Balendra, Y. Qin, A new approach for the optimization of the shrink-fitting of cold-forging dies, J. Journal of Materials Processing Technology. 145 (2004) 215-223.

5. Abdelkhalek S, Montmitonnet P, Potier-Ferry M, Strip flatness model including buckling phenomena during thin strip cold rolling, J. Iron-making and Steelmaking. 37 (2010) 290-297.

6. Abdelkhalek, S, Montmitonnet, P, Potier-Ferry, M,. Coupled approach for flatness prediction in cold rolling of thin strip, J. International Journal of Mechanical Sciences. 53 (2011) 661-675.

7. Yu Meng, Zhang Qingdong, Wang Bo, Research on rolling model based on non-circular contact arc for cold strip temper rolling, J. Advanced Materials Research. 145 (2011) 223-229. 
8. The Iron and Steel Institute of Japan, Theory and Practice in strip or plate rolling (translated by Wang Guodong), M. Chinese Railway Press, Beijing, 1990, pp. 115-119.

9. Zhu Aihua, Zhu Chengjiu, Zhang Weihua, Calculation and analysis of friction torque of rolling bearing, J. Bearing, 6 (2008) 15-18. 